\title{
Disaster Waste Management Research Needs
}

Natural disasters can generate large volumes of debris. In some cases, many years' worth of waste can be generated in a single event - often overwhelming local solid waste management facilities and personnel. Past disasters have led to various emergency measures to manage disaster debris, and the overall response has highlighted the lack of planning. Governments and international institutions seem unable to learn from each others' experiences, and reluctant to fund research to improve our ability to respond.

During the last Intercontinental Landfill Research Symposium (ICLRS), held in June 2010 in Hokkaido, Japan, a session explored disaster waste management. The focus of the session was on research needs and the potential for international collaboration. The research needs were developed into three potential project areas:

- Developing Countries: One of the projects needed would focus on developing countries and would give advice to government and decision-makers in post-disaster situations. This would attack the key issue of a lack of information. We need to give general advice on sites for processing/storage/disposal of post-disaster waste, and provide specific advice through case study analyses. Experienced personnel can give advice tailored to developing countries, and increase awareness in these countries, as well as in aid agencies. In addition, education modules based around the use of case studies need to be developed and trialled. The model for these could be similar to "best management practice" guidelines.

- Emergency Temporary Storage Areas: The second project area would focus on the design, operation, and monitoring of temporary storage facilities. The pressure to clean up after disasters can often lead to poor temporary disposal, and to inadequate segregation of wastes. Each of these factors inhibits reuse and leads to double-handling of waste 
during recovery, resulting in additional costs and time. Research is needed to investigate how these temporary facilities would differ from standard landfills in their design and construction (i.e. cover, liner, gas control, or compaction). We must consider appropriate waste acceptance criteria, and link that to issues of waste segregation. We also need to study how to use or open up the facilities once demand had increased during the recovery phase. Research should examine what environmental monitoring would be appropriate for these facilities. All of these factors would need to consider that requirements might vary as the region turned to normalcy, that details would vary depending on what material was stored, and the materials that should be stored would vary depending on risk, cost, and post-disaster demand.

- Database and Information Sharing: The third project needed would develop a freely available case study database and information source for disaster waste management. We need to bring the diverse case study experiences into one repository, and translate key documents into English. The case studies would be analysed for points of relevance. The database would work like an expert system where users could provide a number of characteristics of interest (eg, type of disaster), and the database would propose the most relevant case studies. This effort would require the development of an international network of researchers and personnel.

Disaster waste causes economic, environmental, and social effects that are still largely underestimated and misunderstood. Disaster waste can be presented as more of a logistical technical exercise than an action that must be integrated into both the emergency response/recovery system and the solid waste management system. Rather than conduct more reactive and country-specific investigations, I hope that we can form multi-disciplinary, multi-national teams to provide the knowledge needed to respond better to future disasters. 
Mark Milke

Dept. of Civil and Natural Resources Engineering University of Canterbury

Christchurch, New Zealand

E-mail address: Mark.milke@_canterbury.ac.nz.

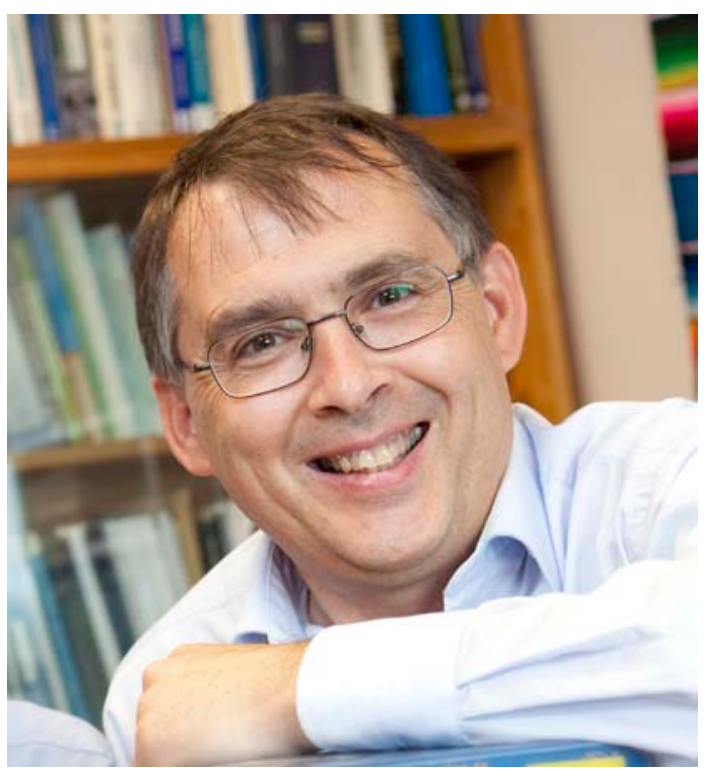

Mark Milke is a Reader in the Department of Civil and Natural Resources Engineering of the University of Canterbury, where he has been since 1991. Born in 1960 in the USA, Mark has published on a wide variety of solid waste topics. He has taught a Solid Waste Management course since 1992 and is the lead author of the solid waste chapter for the Wiley textbook, Introduction to Environmental Engineering. He is currently supervising solid waste research into the costs in developing countries, anaerobic degradation, and disaster waste management. He is a member of the Managing Board of IWWG and served as an Associate Editor for the international research journal Waste Management from 2002 until 2010. 